\title{
Diferentes matizes da idéia de solidariedade
}

\author{
Vera Herweg Westphal \\ Universidade Federal de Santa Catarina (UFSC)
}

\section{Diferentes matizes da idéia de solidariedade}

Resumo: Este artigo analisa os diferentes sentidos do termo solidariedade, identificando que não há uma abundância em teorias sobre este mesmo, mas é tema na sociologia, na filosofia e na política. Resgata a origem do termo quando tinha o sentido de unidade e de auxílio ao próximo. Contextualiza o termo na modernidade, apresentando seu uso no solidarismo francês, na doutrina social da igreja e do movimento de classe dos trabalhadores e na adoção da solidariedade como princípio de Estado, quando fornece suporte à formulação de políticas sociais. Por fim, aborda o termo na economia solidária, constatando seu o uso na forma lingüística de adjetivo, além de sua apresentação com a conotação de algo a ser construído e vivido entre iguais, quais sejam, entre os excluídos de esfera econômica dominante. Reflete acerca do uso do termo na economia solidária, tendo em vista sua construção social e histórica.

Palavras-chave: solidariedade, economia solidária, solidarismo, política social.

\section{Different Notions of Solidarity}

Abstract: This article analyzes the different meanings of the term solidarity. There are not many theories about this theme, although it is debated in the fields of sociology, philosophy and political science. The paper looks at the origin of the term when it had the meaning of unity and assistance to others. The term is considered in the context of modernity, presenting its use in the French solidarity movement, in the social doctrine of the church, in the working class movement and in the adoption of solidarity as a Government principle that guides social policies. Finally, it considers the term of solidarity economics, and finds that the use of the linguistic form of the adjective, in addition to its presentation with the connotation of something to be built and lived among equals, whoever they are, and among those excluded from the dominant economic sphere. It reflects on the use of the term solidarity economics, considering its social and historic construction.

Key words: solidarity, economic solidarity, social policy. 


\section{Introdução}

A economia solidária e seus congêneres têm em seu bojo o uso do termo solidariedade. Este tem sido colocado por vezes como adjetivo, como no caso do termo socioeconomia solidária e, por vezes, como substantivo, como por exemplo, no cooperativismo, quando associado ao princípio da autogestão. Notase, contudo, que há uma predominância no uso do termo 'solidário' como adjetivo e isso evidencia seu sentido semântico enquanto uma característica e/ou uma qualidade em extensão a um substantivo, ou seja, a idéia da solidariedade não é o núcleo central, mas o complemento de um termo.

No contexto econômico, político e social, o termo solidariedade é polissêmico. Neste sentido, a reflexão e a análise acerca do uso do termo na economia solidária podem elucidar as intencionalidades das formas de organização econômica e social presentes nesta.

A solidariedade é uma categoria dos tempos modernos e, na sua concepção atual, surgiu no início do século 19 , como resposta às realidades decorrentes da sociedade industrial. Hondrich e Koch-Arzberger (1992, p. 9) a definem como uma forma específica de vínculo social, historicamente recente, constantemente desafiada e cuja compreensão está em permanente constituição. Não há uma abundância de teorias da solidariedade, sendo uma das controversas e discutidas categorias, tanto na sociologia como na política e na filosofia. Todavia, nas mais diversas exposições teóricas, podem ser identificados dois aspectos comuns: a) um substrato descritivo da solidariedade, constituindo-se na idéia da relação de reciprocidade entre os membros de um grupo e b) um outro substrato, uma base normativa da solidariedade, presente no cotidiano da política, da filosofia moral e em parte também na sociologia, como encontrado em Bayertz (1998,) Capaldi (1998), Khushf (1998) e Wildt (1998). Além destas, há as análises acerca da concepção da solidariedade no plano estatal, como em Zoll (2000), Metz (1998), Ewald (1993) e Frankenberg (1994),

\section{A solidariedade é uma catego- ria dos tempos modernos e, na sua concepção atual, surgiu no início do século 19, como res- posta às realidades decorren-} tes da sociedade industrial.

\section{Origens da idéia solidariedade}

Na concepção pré-moderna de solidariedade, esta é entendida como amor altruísta ao próximo, tendo sua origem nos termos fraternidade e irmandade. Esse conceito, fraternité, foi adotado na revolução francesa e tornou-se lema de luta para a construção de uma sociedade de cidadãos igualitários. Em consequiência, a concepção de luta da fraternité passou a ter um significado político. Com o início da revolução dos trabalhadores de 1848, passou-se a adotar o conceito de solidarité (BRUNKHORST, 2002).

Segundo Hofmann (apud BRUNKHORST, 2002, p. 10 ), a origem lingüística do termo encontra-se no direito romano. Já Brunkhorst explica que o termo solidariedade significa "sólido". Solidus é o próximo e o seguro. O conceito romano-legal in solidum significa o dever para com o todo, a responsabilidade geral, a culpa coletiva, a obrigação solidária: obligatio in solidum. Um por todos, todos por um. Este mesmo autor esclarece que o pagamento de dívidas contraídas por uma pessoa tornava os avalistas co-responsáveis destas, de forma que estes assumiam o pagamento das dívidas no caso do devedor não conseguir quitá-las. Assim, a obligatio in solidum une pessoas desconhecidas com papéis complementares e interesses heterogêneos por meio de um abstrato meio legal. No latim, a origem da palavra solidariedade se refere à "cooperação responsável de direito civil" (BRUNKHORST, 2002, p. 10).

O conceito de solidariedade tem ainda duas outras fontes: 1) a idéia de unidade pagã-republicana (do grego homonoia e do latim concordia) e amizade civil (do grego philia e do latim amicitia), e 2) a idéia bíblicocristã de fraternidade (fraternitas) e amor ao próximo (caritas) (BRUNKHORST, 2002, p. 12). O significado de fraternidade denota que os cristãos, além dos laços consangüíneos, são irmãos em Cristo. Esta unidade em Cristo compromete-os ao amor ao próximo, que deve ser expresso em atitudes.

Apesar da origem jurídica do conceito, o sentido cristão tem forte influência des nas quais, a solidariedade recai no plano da política e torna-se processo social por intermédio da política social redistributiva.

Este texto apresenta um resgate histórico acerca da idéia de solidariedade, abordando diversas concepções explicativas a partir de reflexões e produções acadêmicas alemãs, pouco conhecidas no contexto brasileiro, e fornecendo, com isso, elementos para refletir o sentido do uso do termo no âmbito da economia solidária. de os primórdios, é nele que os sentimentos de unidade entre as pessoas, independentemente de origem, nacionalidade, religião..., são alentados. O entendimento da solidariedade com este sentido será definida neste texto como solidariedade pré-moderna. Ela não tem imbuída a dimensão e as ações de cunho político estatal, ou seja, prioriza as relações humanas. Esta solidariedade pré-moderna ainda é extensivamente praticada, tendo semelhança com formas 
altruístas de solidariedade, de sentido secular, não necessariamente cristão.

\section{0 solidarismo francês}

A solidariedade é a idéia angular do modelo de sistema social denominado solidarismo. É compreendido como uma síntese do individualismo e do coletivismo (FRERICH apud TRAGL; ZOLL, 2000). O solidarismo desenvolveu-se na virada do século 19 para o século 20, influenciou a filosofia social e a política social francesas e a doutrina social da igreja católica. Apesar de não haver uma concepção unitária do solidarismo, neste a solidariedade tem um conteúdo ético-normativo, objetivando a formulação de uma alternativa nos planos social, econômico e político, com um sentido consensual e universal. Esta perspectiva foi defendida por Charles Gide e Léon Bourgeois (TRAGL, 2000).

Gide $^{1}$ constatou que, no transcorrer das mudanças sociais, passa-se de uma solidariedade natural ou obrigatória (solidarité de fait) para uma solidariedade geral ou desejada (solidarité-devoir). A primeira surge por meio da consciência de pertencimento a uma comunidade, como, por exemplo, a família. As ações do indivíduo são influenciadas por este contexto e têm conseqüências no grupo a que pertence, emanando de interesses e convicções semelhantes, bem como por sentimentos de simpatia (TRAGL, 2000). Todavia esta forma de solidariedade não soluciona os problemas éticos decorrentes da esfera econômica.

A outra forma de solidariedade é a solidariedade desejada ou necessária. A solidariedade desejada advém da solidariedade natural. Quando indivíduos reconhecem que a solidariedade natural pode gerar desigualdades, precisam acionar a solidariedade desejada, com vistas a corrigir falhas de desenvolvimento social. A solidariedade passa, então, a ser uma categoria ética para criar movimentos preventivos para efetivação de liberdade e de humanidade. Gide entende que o caminho para uma sociedade solidária passa pela associação voluntária das pessoas nas mais diversas formas cooperativadas. Estas poderiam revolucionar a ordem econômica. Para que a solidariedade desejada ou necessária torne-se real e efetiva, necessita-se da intervenção do Estado na condição de formulador da legislação social. As idéias de Gide foram linhas de orientação na constituição do sistema de seguridade francês (TRAGL, 2000).

Léon Bourgeois ${ }^{2}$ influenciou sobremaneira o solidarismo francês. Ele parte da idéia do necessário laço de solidariedade entre os indivíduos, instituidora da coesão social. Ele entende que solidariedade funda-se da junção de duas forças: o método científico e a idéia moral (ZOLL, 2000). Para ele, o objetivo do Estado é instituir a justiça entre seus membros. Como a solidariedade 'natural' ou 'objetiva' precisa ser complementada pela solidariedade 'moral', esta última foi ativada na forma do contrato social.

Para Bourgeois, trata-se de provocar a inovação social por meio da solidariedade, pois as pessoas necessitam da solidariedade universal para seu desenvolvimento individual (ZOLL, 2000). A sociedade inovadora é construída sobre um quase-contrato, já que todos os seus membros nascem como devedores da associação humana. Ele abordou ainda acerca da eqüalização social e legal entre devedores (que retira benefícios da solidariedade objetiva em decorrência da cooperação social) e entre avalistas (que são penalizados pela solidariedade objetiva e, mesmo com contribuição cooperada, não obtêm benefício). Segundo ele, é por intermédio da mutualização entre devedores e avalistas que o risco é eqüalizado (GÜLICH apud TRAGL, 2000).

$\mathrm{O}$ 'pacto de solidariedade' de Bourgeois organizou uma doutrina contratual específica, que constrói direito social e doutrina moral ao mesmo tempo (ZOLL, 2000). Nesta visão, a sociedade nunca será suficientemente social: cada indivíduo está sujeito a relação com o outro e está comprometido com a efetivação do bem-estar de si mesmo, bem como com o bemestar do outro (EWALD apud ZOLL, 2000). Conseqüentemente, o Estado tem, para Bourgeois, um papel de coordenação. Sua idéia de contrato está baseada na justiça social. Trata-se de uma necessidade social, que é, ao mesmo tempo, um processo reflexivo de permanente negociação. Assim, por intermédio da política social garante-se coesão social.

\section{A solidariedade na doutrina social cristã}

As igrejas cristãs, sobretudo a católica, desenvolveram uma concepção de solidariedade que influenciou propostas e práticas sociais e políticas no mundo ocidental.

A doutrina social católica (DSC) corresponde à atribuição eclesial no âmbito da evangelização, do diálogo com o mundo, da significação/interpretação da realidade cristã e do fomento para a prática pastoral. A doutrina social católica fundamenta-se em dois pensamentos centrais: o da revelação sobrenatural e o do conhecimento social. Trata-se de uma doutrina social cristã ou ética social e tem três princípios: o ser humano, a subsidiariedade e a solidariedade. A concepção social desenvolveu-se como uma doutrina, sendo seus princípios critérios de julgamento em questões sociais e de diretrizes para a ação (WEILER, 1991).

É no início do século 20 que se desenvolveu um ideário sistemático acerca do pensamento social da igreja $^{3}$. Aqui, exemplarmente, abordar-se-á a doutrina social da igreja católica na Alemanha ${ }^{4}$, a qual é construída sobre três pilares: a) o ensino, b) a ciência e c) o movimento social católico, sendo possível iden- 
tificar dois diferentes temas centrais: a pessoa e a solidariedade.

A DSC baseia-se na visão de que a pessoa é imagem de Deus e a união universal entre todas as pessoas decorre da paternidade de Deus e da irmandade em Cristo. Esta doutrina desenvolveu uma visão com conteúdo ético, influenciando sobremaneira na adoção do princípio da solidariedade ao nível da política social na Alemanha ${ }^{5}$ (SCHÜTZ apud TRAGL, 2000).

As idéias da doutrina social católica tiveram grande influência no desenvolvimento da solidariedade como princípio de Estado. O centro da DSC no início do século 20 foi o solidarismo e este sugere um sistema social-filosófico, não teológico ${ }^{6}$. Todavia, a idéia da figura humana solidária espelha-se na doutrina social católica. Na Alemanha, o solidarismo foi fundado por Heinrich Pesch (1854-1926), posteriormente aprofundado por Gustav Grundlach (1892-1963) e Oswald von Nell-Breuning (1890-1993), recebendo nova orientação por Arthur Fridolin Utz (1908-...) (TRAGL, 2000).

Para Pesch, as mazelas decorrentes da economia capitalista deveriam ser corrigidas por intermédio de ações reformistas, sendo todo membro social responsável para a realização da justiça social. Ele diferencia entre 'solidariedade como fato' e 'solidariedade como obrigação', mas recusa tentativas de fundamentação teórico-contratuais. No seu pensamento, a solidariedade como princípio ético, baseia-se na necessidade de complementaridade da pessoa, diferenciando três subcategorias: 'princípio de direito', 'princípio de formação comunitária' e 'princípio de caridade', sendo que os dois primeiros contribuem sobremaneira para a determinação da relação entre liberdade individual e justiça social (TRAGL, 2000).

Posteriormente, Grundlach e von Nell-Breuning desenvolveram uma concepção mais personalista. Para estes, a pessoa como ser constituinte é a condição para a existência da sociedade, necessitando da vida em comunidade. Todavia, esta tem apenas uma função subsidiária na realização das potencialidades pessoais. A solidariedade é um princípio social ontológico, objetivando a inclusão de todos e a daí resultante responsabilidade entre todos (GRUNDLACH apud TRAGL, 2000). Para Nell-Breuning, há um primado da sociedade sobre o indivíduo, devendo ser a seguridade social organizada sobre o princípio da solidariedade. Com isto, a dignidade da pessoa poderá ser assegurada e o Estado estará comprometido com a garantia do bem-estar de seus cidadãos, sua liberdade e sua autonomia.

Após, Utz desenvolveu uma concepção socialpersonalista de doutrina social, entendendo a solidariedade como universalista, sendo pauta de uma ética social. Ele entende a concretização da solidariedade no interior do Estado de direito, que tem por alvo a liberdade individual e integração social. Para
Utz, o Estado de direito é concomitantemente Estado de bem-estar social. Como ser social, a pessoa tem direito tanto à liberdade, quanto ao apoio e auxílio sociais. Entretanto, por estar a sociedade do trabalho pautada e dependente do esforço livre e do interesse individual, a solidariedade é complementada pela subsidiariedade (TRAGL, 2000). Na Alemanha, as contribuições da DSC foram base da solidariedade como princípio de Estado.

De outro modo, na América Latina não houve o mesmo desenvolvimento científico da DSC, nem elevação do pensamento da solidariedade a um princípio de Estado. Mas, a partir dos anos 1960, ocorreu o desenvolvimento da Teologia da Libertação (TL) ${ }^{7}$ como decorrência da situação histórica, econômica e social vivida no continente. Com base teórica na teoria da dependência ${ }^{8}$ e na análise estrutural-social marxista, a TL procura um caminho para a promoção dos oprimidos, dos sem-dignidade, dos sem-direitos, em pessoas de direito. As comunidades eclesiais de base formam o fundamento social da TL. Trata-se de uma teologia situacional, ancorada no contexto concreto dos atingidos e objetivando uma renovação da prática teológica e social. No processo de aprendizagem dialógica ${ }^{9}$, os atingidos tomam consciência crítica de sua realidade e procuram por soluções que possam preencher sua necessidade de liberdade, autodeterminação e condições de vida digna.

As concepções da DSC eram insuficientes para a realidade latino-americana ${ }^{10}$, pois esta aspira mudanças sociais por meio de reformas institucionais e a TL visa transformação social conduzida pelo povo. O socialismo é defendido pela TL de forma explícita, já que as manifestações estruturais capitalistas como pobreza, exclusão e injustiça, atingem a maioria dos membros da sociedade (GREIS, 1993). A TL é um 'repensar' da fé num contexto de dominação e libertação (LIBÂNIO apud GREIS, 1993), sendo a fé redefinida a partir do contexto dos oprimidos, partindo discursivamente da opção pelos pobres, a fim de construir o reino de Deus aqui e agora (DUSSEL, 1997) ${ }^{11}$.

Além das causas sócio-político-estruturais, há motivações eclesiais para o surgimento da TL, quais sejam o Concílio Vaticano (BORIS, 1998) e a II Assembléia Geral do Episcopado Latino-Americano realizado em 1986 na cidade de Medellín (NEUHOLD, 2000) ${ }^{12}$. Enfim, a pobreza, a falta de liberdades políticas, a revolução cubana, a falta de padres no interior longínquo do continente e o fato da maioria dos padres serem originários das camadas abastadas da sociedade, foram algumas das causas para a busca de novos caminhos no interior da igreja.

A TL não desenvolveu uma concepção autônoma da idéia de solidariedade, sendo entendida na perspectiva das encíclicas católicas e da DSC. Solidariedade é compreendida como meio para criar uma ordem social, na qual cada indivíduo pode participar 
integralmente das possibilidades colocadas pela vida natural e pelas relações sociais (HELFENSTEIN, 1991). A idéia de solidariedade da TL é marcada pelas idéias do sentido comum e do bem-comum. Acredita-se que religiosidade é decorrência da comunidade solidária (BAHMANN, 2003). É possível constatar uma grande importância sobre dois valores: a vida comunitária e a reciprocidade, e a solidariedade. Pelo primeiro, efetivam-se as relações interpessoais. Pelo segundo, a ajuda e apoio mútuos. Com isto, pode-se afirmar que a compreensão de solidariedade da TL pauta-se numa dupla dimensão: 1) como irmandade/ fraternidade e 2) como reciprocidade exercida entre iguais, quais sejam, os excluídos, os dominados, os pobres. Assim, ambas são marcadas por uma concepção pré-moderna de solidariedade.

Pode-se afirmar, com isto, que o conceito de solidariedade daí decorrente é marcado por uma concepção classista e de grupo. Não é uma concepção universalista de solidariedade, mas uma perspectiva quase-universal de solidariedade. Trata-se de ser solidário entre os iguais, sendo iguais os que possuem a mesma pertinência de classe. Trata-se, em primeiro lugar, de solidariedade, libertação e justiça pelos e para com os iguais, os explorados e excluídos.

De outro lado, a vivência da solidariedade pode ser compreendida como 'escolhida' e voluntária em determinados contextos (NEUHOLD, 2000), então o seu exercício no âmbito da TL também tem um significado moderno, bem como sua influência na economia solidária.

\section{Solidariedade de classe ou solidariedade dos trabalhadores}

A solidariedade é um conceito de luta para a classe trabalhadora. Este termo foi utilizado a fim de criar união e para alcançar objetivos comuns entre os trabalhadores. $\mathrm{O}$ apelo tinha a finalidade de evocar o sentimento de pertencimento dos atingidos pela mesma situação, ou seja, enquanto trabalhadores assalariados, e que, por isso, deveriam unir-se e lutar por melhores condições de trabalho e salário. O incentivo para o chamamento da solidariedade eram as condições de vida dos assalariados, a experiência comum da miséria. Após a solidariedade ter sido praticada com o significado de coesão social na França dos anos 1830 e 1840, este termo se firmou nos anos 60 do século 19 com a significação de solidariedade dos trabalhadores (ZOLL, 2000). Esta concepção de solidariedade permeou e desenvolveu-se, sobretudo, no ideário socialista.

Neste contexto, Proudhon, conhecido socialista utópico, desenvolve a idéia de mutualité, cujo significado é reciprocidade e cooperação. No regime da mutualidade todos são reciprocamente clientes, filiados, servos, consistindo a solidariedade nesta que os autores do Manifesto Comunista associam com o 'direito ao trabalho', com a liberdade de trabalho, com a cooperação de crédito (PROUDHON apud ZOLL, 2000). Proudhon motivou para a fundação de Mutuelles, associações de ajuda entre trabalhadores, pré-formas da seguridade social e dos sindicatos, nas quais a solidariedade era aprendida e vivida.

A Primeira Internacional dos Trabalhadores, realizada em 1864, demandou solidariedade entre trabalhadores de diferentes profissões e países. Marx utilizou o termo solidariedade muito raramente, mas sempre com a significação da conexão social dos indivíduos. Para ele, o assalariamento era a condição da interligação entre as pessoas (ZOLL, 2000). A concepção marxiana de solidariedade parte da premissa, de que ações solidárias sobre a base de experiências comuns de exploração e subordinação colocam o instrumento adequado para superação das relações capitalistas de exploração.

Para o anarquista Kropotkin, cujos escritos datam da segunda metade do século 19, a solidariedade é a razão mais profunda para a coesão social (ZOLL, 2000). Para ele, a ajuda mútua entre as pessoas era instintiva, e, por isso, a solidariedade é uma parte da herança evolucionária humana, já observável no mundo animal. A contribuição deste pensador é ter definido a solidariedade como noção moral.

Neste mesmo período, antes mencionado, a solidariedade foi incorporada como conceito-chave no movimento de trabalhadores alemães, podendo-se destacar dois defensores da desta idéia. 1) Ferdinand Lasalle afirmou que a solidariedade se configura no trabalho e, por conseguinte, sua universalização é possível. Entendia ser a solidariedade o laço de interesses comuns. 2) Wilhelm Liebknecht defendeu a concepção da solidariedade como o máximo conceito moral e cultural, a partir do axioma "faça ao teu próximo o que queres que ele te faça" (ZOLL, 2000, p. 62).

Ainda, outro analítico da solidariedade dos trabalhadores nos idos do final do século 19 foi Robert Michels. Ele expressou ser esta uma confluência direta dos antagonismos de classe, sendo alta num país, quando contradições econômicas, sociais, intelectuais, religiosas e tradicionais também forem muito elevadas (MICHELS apud ZOLL, 2000). Para ele, experiência de desigualdade e injustiça leva à prática da solidariedade.

Para Zoll (2000), a solidariedade de trabalhadores coloca um determinado aspecto do termo, qual seja, que a condição de igualdade social e a daí resultante igualdade de interesses unem os assalariados na luta pela efetivação de seus interesses. A solidariedade é vista como certa comunhão, e, em alguns casos, vivida como comunidade coesa. Todavia, uma unidade mundial dos dependentes de salário ainda não está no horizonte. 
$\mathrm{Na}$ análise do mesmo autor, o disciplinamento dos trabalhadores por meio de solidariedade de grupo forçada, a solidariedade coercitiva, tem uma longa tradição, já sendo praticada na associação dos aprendizes. Após a Segunda Guerra Mundial, foram empreendidos grandes esforços na Itália, França e Alemanha, no sentido de tornar a solidariedade dos trabalhadores em solidariedade vivida pela população, e de institucionalizá-la por meio dos sindicatos unitários. Além disso, os acontecimentos dos anos 1950 e 1960 também não modificaram a solidariedade. Em relação à vida do trabalho, há que se superar não apenas insuficiências materiais, mas igualmente a falta de possibilidades de auto-realização no processo produtivo, o estranhamento e funcionalização do trabalho, o ser-objeto e a perda do sentido no processo de trabalho. Zoll entende que a igualdade de direito formal necessita ser acompanhada de eqüidade material a fim de realizar democracia, possibilitando a concretização de uma solidariedade geral.

Em relação à concepção de solidariedade de classe, há dois aspectos a serem destacados: de um lado, a solidariedade de classe modificou-se em política social, organizada e administrada pelo Estado nos sistemas de seguridade social. De outro lado, na atualidade, as organizações de trabalhadores estão sendo desafiadas a repensar as relações de trabalho e redimensionar o conceito de trabalho, já que para a satisfação das necessidades humanas, cada vez menos trabalho vivo é necessário. Isso implica em que os trabalhadores se ocupem com a concepção de solidariedade de classe, associada ao mundo do trabalho. Enfim, trabalhadores não são apenas solidários em suas organizações sindicais, mas também na medida em que colocam exigências à política.

\section{Solidariedade como princípio de Estado}

$\mathrm{Na}$ sociedade medieval a pobreza era vista como destino. O amor cristão ao próximo, as tradicionais obrigações de status ou pertencimento às corporações determinavam as formas de auxílio e ajuda a serem praticadas em tempo de necessidade. O Estado de bem-estar absolutista não praticava nenhuma forma de solidariedade, mas de 'paternalismo de sorte' ou 'despotismo benevolente'. O Estado pré-moderno agiu sobre as estruturas de 'bem-estar' feudais e de castas, e removeu-as. A forma efetiva de segurança firmada para os 'socialmente fracos', era a casa, pelo menos enquanto eles estavam integrados nesta. Todavia, as instâncias societárias (família, vizinhança, vila, comunidade eclesial) perderam de forma crescente a sua função (FRANKENBERG, 1994).

Zoll (2000) analisa ser a solidariedade social tanto a base quanto a prática da política social. Este autor esclarece que a prática do cuidado aos pobres é caridade, benevolência, incluindo diferenças hie- rárquicas entre doador e recebedor. Enquanto o cuidado ao pobre contém a prática da benevolência e da caridade, a solidariedade constitui-se em base da política social. Enquanto a primeira está baseada no amor ao próximo, não desembocando no reconhecimento de direitos estatais, a solidariedade tornou-se um conceito para fundamentar a redistribuição dos riscos sociais.

Com as inseguranças crescentes e os riscos sociais e econômicos a que os trabalhadores estavam expostos, a solidariedade veio a ser um princípio de redistribuição dos mesmos, sendo afiançados pelos sistemas de seguridade social. Em países da Europa Ocidental, os sistemas de solidariedade social são encontrados basicamente em três diferentes modelos de seguridade social, conforme apresentado por Zoll (2000), quais sejam, o modelo dos países escandinavos e belga, desenvolvido a partir das associações de subsídios, o modelo alemão, no qual o Estado estabeleceu a iniciativa de um moderno sistema de seguridade social por meio da legislação com responsabilidade parcial da indústria para acidentes de trabalho (1871), doença (1883), idade e invalidez (1889), e o modelo francês, no qual reformadores se ocuparam intensivamente com a questão social.

Pode-se afirmar que o socialismo e o movimento dos trabalhadores forçaram os Estados europeus à efetivação de uma política social. A legislação de seguridade social de Bismarck nos anos 1880, com um papel precursor, tinha uma posição intermediária entre o liberalismo e o socialismo da época, na medida em que associou o princípio de coação e de obrigação contributiva do empregador, como momentos da intervenção estatal, ao princípio da auto-ajuda coletiva, por meio das caixas de auxílio enquanto instâncias de regulamentação social interna (METZ, 1998). Posteriormente, este se tornou modelo para outros países como a França e a Grã-Bretanha. Os encargos em relação aos riscos, como doença, idade e invalidez, eram assegurados sobre a base de esforços contributivos de empregadores e de trabalhadores. Todavia, vale destacar que o conceito de 'solidariedade' não tinha um papel central, já que para Bismarck trata-se de uma medida preventiva do Estado, pois objetivava integração e coesão social. A solidariedade como princípio de Estado validou-se apenas mais tarde.

Metz (1998) explica que, em fins do século 19, a 'política social' possuía em si três progressivos significados incorporados na organização do Estado de bem-estar: enquanto método, função e prática. Enquanto método, possuía uma perspectiva integrativa da economia, sociedade e política; enquanto função, integrava grupos de conflito por meio da ação estatal; enquanto prática, criou instituições legais de manutenção da vida aos trabalhadores assalariados.

No Estado de bem-estar, que organizou progressivamente as sociedades européias ocidentais desde 
a metade do século 19, a solidariedade passou a ter uma base emocional e tornou-se uma pragmática burocratizada. A concepção de responsabilidade foi progressivamente desindividualizada, transferida para 'estruturas' e 'instituições', ficando os sujeitos desautorizados de ação individual. É um procedimento que marca a segunda fase da modernidade, tornando a emancipação coletiva (METZ, 1998). A responsabilidade tornou-se inominada por meio de 'estruturas', nas quais a idéia e o conceito de solidariedade foram atravessados pela coletividade anônima da administração social, do direito social e da política social estatal, em contraposição a uma concepção personalizada de indivíduos. O autor mencionado afirma que, em fins do século 19, a solidariedade social funcionou apenas na seguridade social. O lado adverso se manifestou ao surgirem cada vez mais contratos sociais baseados em cálculos financeiros com a imposição da lógica das transações de mercado.

O modelo de solidariedade estatal enquanto distribuição dos riscos, culminando no sistema de direito do Estado providência, é, segundo Ewald (1993), reconhecido por quatro elementos centrais: a) em cada prejuízo individual, a perda relacionada é transportada para o todo social, independentemente da causa do prejuízo; b) os custos da perda são transpassados pela vítima à outro em conseqüência de uma determinada compreensão de 'barato', correspondente ao desenvolvimento social; c) os sistemas de responsabilidade jurídica colocam-se contra a natureza, o destino e o imprevisível; d) o "estado social ideal" de socialização dos riscos, sendo este ideal realizável como sistema de segurança social.

Contemporaneamente, as questões acerca do ser do Estado de bem-estar apresentam-se como pontos centrais no entendimento da solidariedade burocrático-administrativa e da solidariedade livre e espontânea. A história da política social mostra que nenhum campo da vida social foi tão ocupado por valores orientadores como o campo do auxílio social, sendo a organização deste essencial para a compreensão da própria sociedade e com isto, para a constituição de sua moral (METZ, 1998).

Enfim, a institucionalização e a burocratização do princípio da solidariedade nos sistemas de seguridade social no Estado de bem-estar, angular na organização do Estado moderno, impessoalizaram as dimensões relacional e humana da solidariedade, tornando-as uma abstração.

\section{Solidariedade, civilidade e reconhecimento}

A solidariedade enquanto civilidade é encontrada em Frankenberg (1994) como o pertencimento formal-legal constituidor da relação de solidariedade civil, abrangendo a lógica do conflito numa sociedade pluralista.

A perspectiva do reconhecimento é abordada por Honneth (1992), ao analisar sua efetivação por meio da valorização social. O reconhecimento social abrange e se efetiva nas dimensões subjetivas, sociais e jurídico-legais, sendo avesso ao indiferente e ao invisível. Na análise deste autor (2003), a visibilidade incorpora a capacidade de uma identificação individual. Assim, reconhecer é garantir justiça. Para ele as relações 'solidárias' são baseadas em estima simétrica, evocando a participação afetiva no que é individualmente especial na outra pessoa. 'Simétrico' significa cada sujeito possuir a chance de experimentar-se e vivenciar-se como valoroso para a sociedade, por meio de seus atributos, resultados e capacidades individuais (HONNETH, 1992).

A reflexão do reconhecimento implica numa política inclusiva, de participação social, tanto no âmbito da produção material (trabalho, renda...) como no do consumo, e também no âmbito da segurança social (proteção social em todas as circunstâncias da vida: velhice, imprevistos pessoais, educação...). Enfim, aponta para a política social.

À guisa de conclusão: decorrências da idéia da solidariedade à economia solidária

Diante do exposto, das diferentes matizes da idéia da solidariedade cabe a reflexão acerca do significado e sentido desta na economia sociossolidária. Estando a solidariedade vinculada tanto a relações interpessoais, no plano micro social, como a ações políticas, na perspectiva macro social, cabe indagar acerca das finalidades das concepções e práticas no âmbito da economia sociossolidária.

Nesta acepção, há indagações acerca do sentido do adjetivo na economia sociossolidária: sua ênfase está no sentido relacional ou estrutural? Ela se confi- 
gura apenas numa economia que se desenvolve e movimenta no interior de outra economia? Ou é uma economia que funciona paralelamente ao modelo econômico dominante, mas ao mesmo tempo necessitando estabelecer determinadas relações, principalmente de troca, com o mesmo?

No uso do termo e na prática da solidariedade na economia solidária é possível constatar uma maior aproximação tanto aos ideais do solidarismo francês como aos da fraternidade cristã. Em ambos, são destacados a consideração e o auxílio aos integrantes de um grupo social, construindo-se coesão coletiva. Com isto, a economia solidária se desenvolve como uma forma de produção e organização compatível no sistema social de forma geral. Já a influência do ideário da doutrina social cristã bem como a condição de classe trabalhadora, e daí a decorrente adoção da solidariedade como princípio de Estado, são mais incipientes na economia solidária. A incorporação deste sentido de solidariedade implica num processo profundo de alteração das estruturas econômicas de uma sociedade, o que ainda está por ser construído, mesmo considerando as iniciativas já em andamento.

Observando as práticas de economia sociossolidária, evidencia-se sobretudo o aspecto da ajuda mútua entre iguais. Já o sentido estrutural da idéia de solidariedade enquanto fundamento da política econômica e social, não é tão límpido e translúcido. A concepção da solidariedade apenas na sua dimensão relacional é insuficiente para a fundamentação normativa da política estatal. Além da dimensão cognitiva, do esclarecimento, a compreensão da idéia de solidariedade demanda reflexão acerca de suas finalidades, seu sentido ético-político. Estas são a questão e a tarefa colocadas à economia solidária, para que possa vir a ter alcance social universal e ser construtora de justiça social.

Em síntese, é possível afirmar que concepções acerca da solidariedade ocupam-se com aspectos descritivos e normativos, incorporando análises pautadas em sentimentos de pertencimento e vivência comunitários, e até análises vinculadas a princípios éticos no campo dos direitos legais. A questão acerca da integração da sociedade por meio da solidariedade, enquanto sentimento ou enquanto princípio de Estado continuará a ser tema teórico e empírico das ciências sociais, sendo sua compreensão relacionada aos crescentes processos de indivi-dualização, modernização e diferenciação da sociedade moderna.

\section{Referências}

BAHMANN, M. K. Der Vorzug der Armen. Frankfurt/Main: Lembeck, 2003.
BAYERTZ, K. Begriff und Problem der Solidarität. In: BAYERTZ, K. (Hg.). Solidarität. Begriff und Probleme. Frankfurt/Main: Suhrkamp, p. 11-53, 1998.

BORIS, D. Soziale Bewegungen in Lateinamerika. Hamburg: VSA, 1998.

BRUNKHORST, H. Solidarität. Von der Bürgerfreundschaft zur Globalen Rechtsgenossenschaft. Frankfurt/Main: Suhrkamp, 2002.

CAPALDI, N. Was stimmt nicht mit der Solidarität? In: BAYERTZ, K. (Hg.). Solidarität. Begriff und Probleme. Frankfurt/Main: Suhrkamp, p. 86-110, 1998.

DUSSEL, E. Transformaciones de los supuestos epistemologicos de la Teologia de la Liberacion. In: HUNGERKAMP, M.; LUTZ, M. (Hg.). Grenzen überschreitende Ethik. Frankfurt/Main: IKO, p. 83-98, 1997.

EWALD, F. Der Vorsorgestaat. Frankfurt/Main: Suhrkamp, 1993.

FRANKENBERG, G. Auf der Suche Nach der Gerechten Gesellschaft. Frankfurt/Main: Fischer, 1994.

GREIS, F. Die Situation der Befreiungstheologie nach dem Scheitern der Dependenztheorie und dem Zusammenbruch des Sozialismus. Universität Mainz, 1993. Disponível em: <http://www.goldlay.de/haus/ anz1.html\#Heading6>. Acesso em: 10 mar. 2004.

HELFENSTEIN, P. F. Evangelikale Theologie der Befreiung: Das Reich Gottes in der Theologie der Fraternidad Teológica Lationoamericana und der Gängigen Befreiungstheologie, ein Vergleich. Zürich: Theol. Verl., 1991.

HONDRICH, K. O.; KOCH-ARZBERGER, C. Solidarität in der Modernen Gesellschaft Frankfurt/Main: Fischer, 1992.

HONNETH, A. Muster intersubjektiver Anerkennung: Liebe, Recht, Solidarität. In: Ders.: Kampf um Anerkennung. Zur Moralischen Grammatik Sozialer Konflikte. Surhkamp: Frankfurt/Main, p. 148-211, 1992.

HONNETH, A. Unsichtbarkeit: Stationen einer Theorie der Intersubjektivität. Surhkamp: Frankfurt/Main, 2003.

KHUSHF, G. Solidarität als moralischer und politischer Begriff. Jenseits der Sackgasse von Liberalismus und Kommunitarismus. In: BAYERTZ, K. (Hg.). Solidarität. Begriff und Probleme. Frankfurt/Main: Suhrkamp, p.111$145,1998$.

LENSCHEN, D. Produktivgenossenschaften und Katholische Soziallehre: Eine Historische und 
Systematische Untersuchung zur Idee der Produktivgenossenschaften in der Katholisch-sozialen Bewegung. Paderborn, 1997. (Dissertation in Theologie)

METZ, K. H. Solidarität und Geschichte. Institutionen und Sozialer Begriff der Solidarität in Westeuropa im 19. Jahrhundert. In: BAYERTZ, K. (Hg.). Solidarität. Begriff und Probleme. Frankfurt/Main: Suhrkamp, p.172-194, 1998.

NEUHOLD, L. Religion und Katholische Soziallehre im Wandel vor Allem der Werte: Erscheinungsbilder und Chancen. Münster: LIT, 2000.

TRAGL, T. Solidarität und Sozialstaat. Theoretische Grundlagen, Probleme und Perspektiven des Modernen Sozialpolitischen Solidaritätskonzeptes. München; Mering: Hampp, 2000.

WEILER, R. Einführung in die Katholische Soziallehre. Ein Systematischer Abriss. Graz; Wien; Köln: Styria, 1991.

WILDT, A. Solidarität - Begriffsgeschichte und Definitionen Heute. In: BAYERTZ, K. (Hg.). Solidarität. Begriff und Probleme. Frankfurt/Main: Suhrkamp, p. 202209, 1998

WÖHLKE, M. Grundzüge der Dependenz-Theorie - Eine Einführung. In: ALT, G. und WROBÈL-LEIPOLD, A. (Hg.). Armut im Süden Durch Wohlstand im Norden. Nachträge und Schlaglichter zur Dependenz-Theorie. Vilsbiburg: Hanns-Seidel-Stiftung, p. 17-34, 1998.

ZOLL, R. Was Ist Solidarität Heute? Frankfurt/Main: Suhrkamp, 2000.

\section{Notas}

1 Charles Gide foi um influente economista na Franca e viveu de 1847 até 1932 (ZOLL, 2000).

2 Léon Bourgeois (1851-1925) era vinculado ao partido Radicaux-Socialistes, foi político e primeiro ministro, influenciando fortemente o sistema de seguridade social francês (ZOLL, 2000).

3 Os documentos papais, as encíclicas Rerum Novarum (1891), Quadragesimo Anno (1931), Mater et Magister (1961) e Pacem in Terris (1963), a Constituição Pastoral Gaudium et Spes (1965) e as encíclicas mais novas, Populorum Progressio (1967), Sollicitudo Rei Solialis (1987)e Centesimo Anno (1991), são os pontos de partida da DSC.

4 A inclusão deste exemplo foi decisão da autora do artigo, por ter pesquisado este tema durante a elaboração de sua tese de doutorado, em 2004.
5 Vale esclarecer que o protestantismo não teve influências significativas no âmbito da política social naAlemanha.

6 Já na segunda metade do século 19, pessoas como Wilhelm Emmanuell von Ketteler, Franz Hitze, Friedrich Eberl, St Paulus-Innung zu Lübbecke se ocuparam com as orientações práticas da encíclica Rerum Novarum. Eles apoiavam a idéia da organização de cooperativas produtivas como resposta à questão social. Para isto Lenschen (1997) desenvolveu um estudo histórico e relacionou as cooperativas de produção com a doutrina social católica em fins do século 19 e início do 20.

7 Alguns de seus representantes: Gustavo Gutierrez,Jon Sobrino, MiguezBonino,Leonardo Boff,Clodovis Boff,HugoAssmann. Não há uma concepção unitária na teologia da libertação. Ela influenciou outras direções teológicas, como por exemplo, a teologianegra, africana, feminista(NEUHOLD, 2000).

8 Esta esclarece ser o retrocesso e a dependência da América Latina causados pelo tipo de relação estabelecida entre países desenvolvidos e subdesenvolvidos. Estabelece-se uma integração assimétrica dos países periféricos por meio de uma dependência estrutural. Wölhke (1988, p. 23) explica que a dependência estrutural continha uma coordenação do desenvolvimento de fora dos países periféricos por parte dos países industrializados desenvolvidos; forçando disparidades estruturais internas (heterogeneidade estrutural), e permitindo apenas um desenvolvimento deformado, assim desembocandoem formas específicas de subdesenvolvimento social (marginalidade). Vale esclarecer que a Teologia da Libertação pensa o modelo da libertação, não do desenvolvimento.

9 A concepção de uma educação libertadora de Paulo Freire teve um importante papel, na medida em que propôs uma concepção teórica e metodológica no trabalho com grupos de base.

10 Istoé afirmado pelos representantes da Teologia da Libertação (TL): Delgado, Gutiérrez e Boff (apud NEUHOLD, 2000). Atualmente a relação entre doutrina social católica e TL, é definida pelos teólogos da TL como aberta e positiva. Kruip (ibidem) enumera seis críticas da TL para a DSC: 1) pouca relevância de mudanças históricas; 2) eurocentrismo; 3) análise social deficiente; 4) falta de valoração das estruturas sociais; 5) omissão do caráter de conflito da sociedade; 6) comportamento social da igreja baseado somente pelo julgamento de ganhos e perdas.

11 Neste texto Dussel expõe a atualidade da TL e esclarece suas transformações epistemológicas nos últimos anos, por exemplo, o significado do paradigma lingüístico: subjetividade comunitária, consenso crítico, fundamentos éticos e econômicos, pobreza como vítima social, razão estratégicademocrática, meta-teologia, ecumenismo. 
12 Vale esclarecer que a TL foi incorporada apenas de forma tímida pelo protestantismo. Na Igreja Evangélica de Confissão Luterana no Brasil (IECLB), os teólogos da TL se agrupam na Pastoral Popular Luterana (PPL).

\section{Vera Herweg Westphal}

Doutora em Sociologia pela Westfäliche Wilhelms Universität/Münster, Alemanha

Professora do Departamento de Serviço Social, da Universidade Federal de Santa Catarina (UFSC)

\section{UFSC}

Campus Universitário Reitor João David Ferreira Lima

Bairro Trindade

Florianópolis - Santa Catarina

CEP: 88040-970 